\title{
Performance of different constitutive soil models: from element tests to the simulation of vibratory pile driving tests
}

\author{
Jan Machaček ${ }^{*}+$ Patrick Staubach $^{\dagger}$, Merita Tafili ${ }^{\dagger}$, Hauke Zachert ${ }^{\dagger}$, Torsten Wichtmann ${ }^{\dagger}$ \\ * Technical University of Darmstadt, \\ Department of Civil and Environmental Engineering, \\ Institute of Geotechnics, Germany \\ "e-mail: jan.machacek@geotechnik.tu-darmstadt.de \\ $\dagger^{\dagger}$ Ruhr University Bochum, \\ Department of Civil and Environmental Engineering, \\ Chair of Soil Mechanics, Foundation Engineering and Environmental Geotechnics, Germany
}

\begin{abstract}
After decades of developing advanced constitutive soil models, what fruits can be harvested? Can they help solve complex geotechnical problems? Are these models accurate enough? Is the exact procedure for calibrating these models known and also implementable? The range of available constitutive soil models extends from simple linear to time-dependent and hydromechanically coupled nonlinear modelling approaches. It is the user's task to select a constitutive model suitable for his problem at hand. This requires in-depth knowledge of the material behaviour of the soil as well as the strengths and weaknesses of the available constitutive models, most of which have only been validated using element test simulations. The procedure from parameter calibration using laboratory tests under welldefined boundary conditions (element tests) to the simulation of boundary value problems is complex in many respects and is often not followed with advanced constitutive models due to the large number of parameters required and the necessary laboratory tests (monotonic/cyclic as well as drained/undrained conditions). In this paper, the prediction quality of three advanced constitutive models is investigated in detail, namely the Hypoplasticity with Intergranular Strain, the Sanisand and the Hypoplasticity with Intergranular Strain Anisotropy models. The investigation is carried out based on recalculations of laboratory tests and well-documented model tests for their suitability to represent complex soil mechanical aspects, such as the material behaviour at small and large strain, virgin loading and unloading, cyclic loading and pore pressure accumulation. The laboratory tests include oedometer tests, monotonic and cyclic triaxial tests, which have been carried out on Karlsruhe (KA) sand. Subsequently, model tests of vibratory pile driving in water-saturated KA sand are simulated using the previously calibrated parameters. The strengths and weaknesses of the above-mentioned material models in representing the soil behaviour are shown by detailed comparisons with the measured results.
\end{abstract}

